\title{
The Impact of Adopting a Mainstreamed Model of Service Provision: The Experiences of University Staff Members
}

\author{
Sophia A. Harryba \\ Edith Cowan University \\ Shirlee-ann Knight \\ Edith Cowan University \\ Australia
}

A qualitative case study examined the challenges of service provision and utilization regarding international students at an Australian university. Using a Social Constructivist Grounded Theory methodology, 73 participants were interviewed, including 38 staff members (16 academic, 22 non-academic), 25 international students, and 10 domestic students. The university had recently changed its model of service provision from specialised to mainstreamed. All students became viewed as one cohort, with the same needs, accessing the same services. Challenges associated with this move were discussed, and it was found that opinions about the effects of the new model depended on the staff members' role at the university and how much contact they had with international students. Teaching and support staff members reported struggling when working with international students under this model of service provision, and staff members reported facing challenges in providing support outside of their role descriptions, lack of specialised staff, and lack of specialised services. It was concluded that the use of this model, added to increasing enrolment numbers and decreasing support both for staff and students, could lead to an increased likelihood that some staff view and treat some international students with a "deficit" lens.

\author{
Mainstreamed vs. Specialised Student Service Provision \\ Students as Customers \\ Evaluating Student Services in a Market Economy \\ Limitation of Previous Research \\ The Study \\ Results and Findings \\ Conclusion and Implications \\ Notes
}

In 2008, International Education (IE) was Australia's third highest export after coal and iron ore, providing more than $\$ 15$ billion per annum to the economy (Department of Education, Employment and Workplace Relations, 2008). IE has become one of the most significant exports for countries such as the United States, United Kingdom and Australia, which make up the top three Anglophone countries exporting education (Pimpa, 2003). As a competitive industry, universities within host countries have to attract these international 
students so as to guarantee a continued flow of money to the economy, but also to ensure that universities reach their minimum annual intake of students (Paige, 1990). Income from international student fees is needed for a number of purposes: to fund infrastructure and research, to cover staff salaries, and to pay for other goods and services used by onshore students (Beaton-Wells \& Thompson, 2011; McKenzie, 2008). This income comes not only from international students' tuition fees, but also from the travel and living expenses of these international students, their dependents, and visiting families and friends (Phillimore \& Koshy, 2010). In addition to the economic benefits that IE brings, it has been reported that international students bring a number of social and cultural benefits as well (Carroll \& Ryan, 2005). Studies have found that international students promote intercultural interaction (Kell \& Vogl, 2008; Mahat \& Hourigan, 2007), help reduce discrimination, and increase tolerance for different cultures (Bochner, 1986; de Wit, 1995; Gudykunst, 1998).

Given the economic and sociocultural value of IE in Australia, concerns have been raised since there has been a general decline in commencement and enrolment numbers of onshore international students since the global recession began in 2008 (Pelletier, 2004). This qualitative study explores how an Australian university handles student services, particularly to international students, on campus.

\section{Mainstreamed vs. Specialised Student Service Provision}

Research has shown that international students can experience a number of academic and socio-cultural difficulties when transitioning to university (Mehdizadeh \& Scott, 2005; Rahman \& Rollock, 2004; Searle \& Ward, 1990; Trice, 2003). Tinto's model of student departure (Tinto, 1975) and other variations of this model (Bean \& Metzner, 1985) suggest that the cost of student dropout is greater than the cost of providing appropriate support services to these students. Thus, depending on the model of service provision adopted by individual universities, different types of services aimed at different student cohorts have been developed to help lessen these student difficulties. Currently, there is limited research that focuses on the implications of the different models of service provision.

Forbes-Mewett (2008) compared the specialised model of student support with the mainstream model as follows:

Specialised student support allows for subjective elements and at the very least provides international students with a first point of call dedicated to catering for their unique needs. Mainstreaming, by contrast, assumes the problems of international and domestic students are largely homogenous, that neither group requires the assistance of professionals with specific skills, and that both can be provided for in the same manner. (p. 2)

Mainstream models of student service provision assume that problems faced by university students, whether domestic or international, are largely homogenous 
and are based on the belief that student groups do not require any specialised help (Forbes-Mewett, 2008). The effectiveness of basing university-wide approaches to student support on the assumption that students' needs are largely the same was questioned by Forbes-Mewett who found that the university senior managers she interviewed admitted they had little to no contact with international students and lacked knowledge about their needs.

Further, Schulz and Szekeres (2008) found that student services as a whole lacked on-the-ground efficiency when provided under a centralized model and that customer (i.e., student) satisfaction was needed to be considered when deciding which aspects of student administration services to offer centrally. They concluded that "a range of considerations" including "cost efficiency, consistency, customer satisfaction, process logic and institutional culture" needed to be evaluated continuously when considering university approaches to student support and administration (p. 269).

\section{Students as Customers}

There has been much debate regarding the use of marketing and business terminology, such as "customers" and "service providers" when referring to stakeholder in higher education (Baldwin, 1994; Hill, 1995; Pitman, 2000; Ramachandran, 2010; Scott, 1999; Small, 2008). For most international students, full fees are required for their education; as a result, they may view themselves as customers and expect value for their money (Moodie, 2010). The use of marketing terminologies is not always popular with certain staff members, who may not see themselves as "service providers," as this means students may be perceived as the customer, which can inadvertently imply a view that "customers are always right." Small (2008) found, however, that staff members see their roles more along the lines of pastoral care rather than as the series of "transactions" that using marketing terminologies would suggest.

In the university conceptualised as being a market economy, there is more than one group of "customers." That is, customers are not only students but also other stakeholders such as academics (Conway, Mackay \& Yorke, 1994). Further, Ramachandran (2010) argues that even if a marketing metaphor is used to describe the higher education sector, "higher education' products are different from 'commercial products' and students are different from 'customers' who buy commercial products" (p. 544). Nevertheless, there are numerous marketing strategies employed at the university level as well as globally to entice students to specific institutions and host countries. These include ranking systems for universities, for example the ranking system developed by the Shanghai Jiao Tong University that evaluates universities worldwide based on their research output, as well as the use of surveys such as the international student barometer and Unit and Teaching Evaluation Instruments (Australian Education International, 2010) to provide insight into student's expectations and experiences at universities (Lynch, 2006; Marginson, 2007). Meek (2000) 
suggests such measures and performance benchmarking are "intended to increase competition and ensure value-for-money and efficiency gains" (p. 25).

\section{Evaluating Student Services in a Market Economy}

SERVQUAL surveys have been adapted by a number of researchers (Arambewela \& Hall, 2009; Oldfield \& Baron, 2000; O'Neill \& Palmer, 2004; Tan \& Kek, 2004) to understand students' evaluation of service quality at universities. Surveys such as these can increase universities' awareness of what students perceive as necessary services as well as help universities to gauge how satisfied their students are. Conversely, it has been argued that because services are different from goods in that the former is not tangible, perishable, or separable from production and consumption, it is difficult for standardised surveys to properly conceptualise and therefore properly evaluate university services (Hill, 1995).

University services often involve human interaction and can be labourintensive and as such are generally heterogeneous "as each service act is unique" (Hill, 1995, p.12). This can lead to a lack of standardisation and considerable quality variation from "one situation to the next within the same organization" (p.12). Further, Hill (1995) adds that "service productivity and quality depend not only on the performance of the service provider's personnel, but also on the performance of the consumer, which again can make quality management problematic" (p. 13). For example, if a student fails a unit or dislikes a staff member, the impact on the student's evaluations of a service may have little or nothing to do with the quality of that service or its provision. The consumer, it has been argued, relies on cognitive scripts of their expectations of the services, as well as on their previous experience with similar services, to evaluate subsequent services. For many international students, word of mouth is an important predictor of whether or not prospective students will choose particular universities and host countries. Therefore, when evaluations are based on expectations and past experiences, it might impact on this channel of advertising. Nevertheless, the climate prevails in which education institutions are engaged in competitive battle for student numbers (Sines \& Duckworth, 1994), and this means that universities are required to operate in a quasi-market fashion, where student/customer satisfaction is paramount and these customers have more say into decision making. In this climate, universities are adopting business models and now perceive themselves to some extent as providing services (Scott, 1999). Therefore, as customers of higher education, full-feepaying students, including international students, have a growing expectation that they be provided with access to services which are culturally appropriate and specifically designed to cater for their unique needs. 


\section{Limitations of Previous Research}

The current body of research into university international student services provision has a number of limitations. Studies have tended either to focus on the broad generic services provided by universities (Dhillon, McGowan, \& Wang, 2008; Franke \& Arvidsson, 2010), or on specialised services provided only for international students (McKinlay, Pattison \& Gross, 1996; Ramsey, Jones \& Barker, 2007; Seow, 2006). Mostly, these studies have been small scale or did not explain in depth the complexities of issues. Looking at both the generic and specialised services provided by one institution, this study provides a more holistic view of how the model of service provision affects the staff and students who provide and utilise services at university. In addition, there has been limited research focusing on staff perspectives of service provision, which has made it difficult to evaluate, from a service provision perspective, the pros and cons of available models of service provision.

Taking into account the limitations discussed, the current study aimed to understand the challenges of service provision and utilisation from a more holistic point of view, using semi-structured interviews that took into account the perspectives of all three cohorts involved, namely staff members, domestic students, and international students.

\section{The Study}

Understanding realities from the different perspectives of individuals is the essence of social constructivism, which sees each individual's experiential story as true and valid at one iteration because it has been experienced and is a perception of that experience (Manis \& Meltzer, 1972). Thus Social constructivism formed the basis for this study that was designed to allow the researchers to develop a rich picture of the complex interactions involved and allow for development of better-tailored services for all parties within the case university. This paper focuses on one of the themes that emerged from the whole study: i.e., the experiences of staff members when working with international students within a mainstream model of service provision.

\section{Methodology}

The study adopted a social constructivist (Charmaz, 2000) theoretical framework to explore the challenges of accessing and providing international student services at one "case" university. The university was conceptualised as a "case" since literature argues that each institution has its own specific characteristics, budget, and student population and therefore is best studied separately (David \& Renea, 2008). This approach firstly allowed the researchers to develop a critical understanding of the intricacies of the single case, including the student/staff and the staff/institution relationships (Calder, 2004). Secondly, 
since service provision and utilisation are complex issues, multiple realities of the different stakeholders involved were explored more deeply.

Social constructivism argues that reality is subjective to the person experiencing it and so social constructivism was able to frame the anticipated complexity of the research design. Data collection and analysis strategies associated with "constructivist grounded theory" (CGT) helped to conceptualise and triangulate responses from the different cohorts being interviewed and allowed for theoretical sampling, which permitted the researchers to follow up new directions in subsequent interviews as themes emerged during data analysis (Charmaz, 2000, 2006).

One such theme that emerged within the current case provided a unique investigative setting for the researchers and is presented in this article. Just prior to the interviews, the Case University (CU) had changed its university-wide model of student service provision from specialised heterogeneous services to mainstreamed homogenous services. This provided an opportunity to investigate the challenges associated with providing and accessing services under a mainstream model of service provision from the perspective of the changes being experienced by all interviewed cohorts.

\section{Data Collection}

A total of 73 participants were interviewed from three different cohorts, namely staff, domestic students, and international students. Data saturation (Fossey, Harvey, McDermott, \& Davidson, 2002; Morse, 1995) was reached at different points for the different cohorts, as well as for the questions contained in the semi-structured interviews. For staff members, saturation was reached at 38 , made up of 28 females and 10 males who were a mix of academic and nonacademic/support staff (see Figure 1). Saturation for international students was reached at 25 since the interview questions were more specific in nature than for staff, with the most specific interview-that of domestic students-reaching saturation at 10 participants.

Figure 1: Demographic Information: University Staff \& International Students

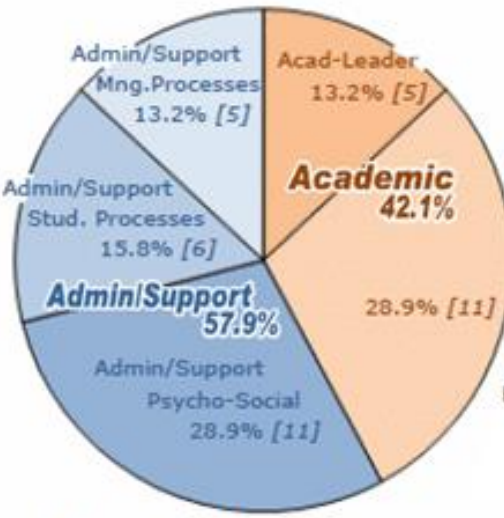

Figure la: Mix of academic vs. non-academic staff interviewed
BF = Business Faculty * $E F=$ Education Faculty ${ }^{*}$ $\mathrm{SF}=$ Science Faculty $*$ * generic faculty names

\section{Figure 1b: International students} $(n=25)$ according to enrolled 
Three evolving interview schedules developed, one for each cohort of participants. The questions evolved slightly as the process of theoretical samplin facilitated new directions in enquiry (Strauss \& Corbin, 1990). Notes were taken during the interviews, which were compiled into a reflective journal (Glesne, 1999). This journal also included the primary interviewer's thought processes during and after data analysis. Data were manually analysed and stored using NVivo8 software. Participants were recruited using invitational emails, flyers and website posts, followed by snowball techniques. Interviews ranged from 30 to 60 minutes long, and data were transcribed after each interview.

\section{Data Analysis}

Data were analysed using techniques associated with CGT (Charmaz, $2000 \& 2006)$. The process is illustrated in Figure 2. Transcribing was done immediately after each interview so that a constant comparison (Strauss \& Corbin, 1990; Charmaz, 2000; Moghaddam, 2006) of previously data collected could be carried out before and then during the process of further interviewing. The notes taken during each interview were reviewed before the next interview to gain a broad sense of what the interview was about. Although there was a set of (semi-structured) questions, most participants had individual overriding issues that were returned to throughout their interview.

Figure 2: Phases of Grounded Theory (Moghaddam, 2006)

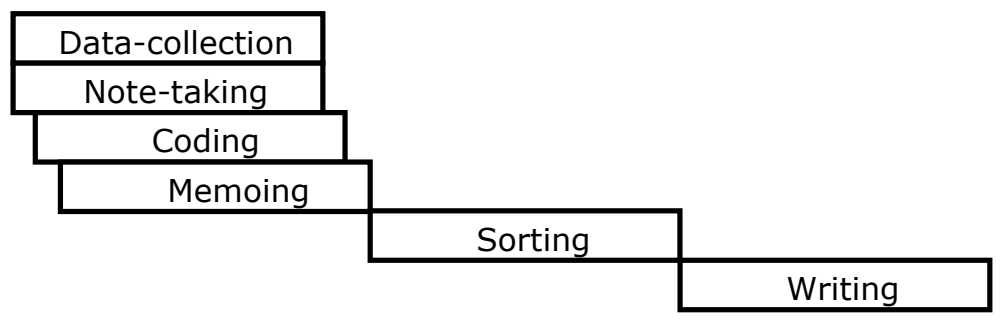

\section{Results and Findings}

CU moved from offering specific services for international students to a more generic, centralised model of service provision around 2007, some 18 months prior to the interview period of this research. The reason given for this change in service provision depended on which participants were being interviewed. One support staff member suggested it was possible that CU was simply following other universities also changing to a generic model of service provision. Another staff member, who was a member of the university's senior management, suggested the change came about after the leadership was changed at the university. This leadership change wanted to reflect the One University: Students First initiative, which meant that all students accessed the same services. According to the staff member, the change was meant to avoid "segregating" international students by offering them separate services from those provided to domestic students. Following this argument, offering generic services would, therefore, bring domestic and international students together. 
The interviews reveal, however, that both cohorts of students reported experiencing a lack of intercultural interactions, and so it would appear that the centralised, generic model was not achieving that aim.

There's a philosophical debate...There's one side that believes the best way to serve international students is to have them fully integrated with the Australian students, and there's another side...that says, international students have got different needs from the Australian students, and therefore we need to have specialised services only for the international. Now three years ago and beyond we were on this [specialised] side of the spectrum where we had international student support as part of $\mathrm{CU}$ International and they had award winning services and programs for international students. However, while that was in place, there was a grave concern that the international students were not integrating with the Australian students, so when we had a change of leadership within the university the new leaders went to the other side, to say...you shouldn't segregate international students, they are all students. So we basically transitioned from that model to the model that we are currently operating under where all students report to the one place irrespective of where they come from, and hopefully that service centre is adequately meeting the needs of international students. I think that the student services centre, once they started actually dealing with international students, started to realise how different they were from the Australian students and they are trying to get to the level of support that international students need, however they are reinventing the wheel that already existed, because they didn't take anything from the previous model.

\section{International and Domestic Students Have Different Needs}

Under the revised model, the first point of reference for all students who require help or information is the student information unit where they queue up and take a number to see a student advisor. If the student advisors cannot help, students are asked to make an appointment with "connect officers," which can take more time:

The way SSC (student services centre) is set up is everybody comes through the front. It's [like an] imaginary front counter and the enquiries are floated down through there...if somebody just has a quick question that kind of thing that's fine, but for specialised queries? You wonder if they're equipped to deal with international students. So crazy.

In the interviews, staff members argued that the centralised system does not work as well for international students who are shy or who lack confidence in their conversational English skills. A staff member noted that international students need privacy to discuss some of their issues, and the student information unit is an open space where other students can overhear the international students. Further, some staff members argued that staff in the student information unit were often very busy with multiple queries and did not 
have the time to sit, listen, and try to understand what an international student needs. A noted change was that before the change in model provision, international students had access to a one-stop-shop and contact with staff members who were well-versed with the needs of these students; now they had to access the same services that the domestic students access.

Changes to service policy within the university furthered the debate along equity lines, as the move to generic service provision had not been seen as a good initiative by certain staff. In particular, staff felt their opinions were not taken into account by the university when considering how to implement new policy:

We had a team of international student support, and that team, over many years, [had] come up with the services they were providing, and there was method in what they did and there were reasons why they did what they did. When we transferred away from international student support being part of $\mathrm{CU}$ International to the student services centre, I'm not aware of any knowledge or systems or processes or services that were transferred from us to the student centre services.

Further, the move from specialised to generic services for all students was seen as "ignorant" by staff members who argued that international students required specialised help:

I think CU made a mistake getting rid of the international student advisers. That was a department that specialised in that area; they knew what they were talking about. We used to deal with them a lot and they used to advocate for students at appeals and that sort of thing... just don't understand where $\mathrm{CU}$ are coming from by saying everyone has the same problems. It's just ignorant to say that. I mean obviously international students have so many more issues to contend with. You know homesickness, culture shock...shame and the whole thing of not knowing where to go for help and being isolated and just so many different issues that domestic students are never going to face.

This view was expressed by academic staff members as well as nonacademic/support staff:

A lot of the support services have been centralised so we are losing our student support officer and I know that a plan by the university to optimise its resources and streamline them but I don't know that that's appropriate, particularly in a school that has so many international students.

While arguing their point that international students have different needs compared to domestic students, one staff member suggested that since the university has enrolled them, there should be a duty of care to make sure international students are taken care of, through better emotional support:

They need often an awful lot of support. International students face separation from their families, their support networks, everything that they need to get along in life basically. They come to a country...they don't know anyone, they don't know how the country works, or what the culture 
is like...that would make you feel very isolated and alone and there needs to be more social and emotional support. Now that may not be the university's job, but the university takes their money, there should be a duty of care somewhere, as far as I'm concerned.

For the staff members who had worked under the old model, there was general agreement that it worked better both for the staff members and international students. In that model, the international office catered not only for admissions, but also offered services such as international student officers (ISOs) who were always on campus and had private offices for international students to discuss their issues and who also had time to work with these students through any issues. Some ISOs were multilingual, which helped international students who lacked confidence in their English skills. They were also well versed with the immigration and VISA requirements for students and held a number of social activities, through the international student groups (e.g., Kenyan students group and Chinese students association). As staff members pointed out, this department was specialised in that they had experience in dealing with international student issues. They advocated for and understood the needs that international students have. It was expressed that, at present, these students' needs were no longer being met, as there were no programs or services being offered to take into account all the academic and socio-cultural difficulties international students can experience.

\section{Lack of Specialised Staff}

Staff members argued that with the move to a centralised, generic model and the resultant changes that were happening at the university, there was now a lack of staff members trained to work with international students. Some staff were explicit and animated when suggesting that the university had to realise that with the growing number of international students, there needed to be more staff members being employed to work specifically with these students. As an emergent theme in the data, lack of support staff posed the biggest challenge in international student service provision:

It's very hard for us to meet the needs of all our students, both international and local with that number of staff. We're trying to address it through a series of workshops but my feeling too is that there's a great need for individual consultation [with international students] and it's hard to accommodate the needs of all those students with so few of us.

Academic staff members expressed that the ratio of learning advisors to the number of enrolled international students was too low and that the university executives were out of touch with the pressures they faced in teaching these students:

There has to be much better support systems...three or four learning advisers for the whole university, is just ludicrous...and I think that the problem with $\mathrm{CU}$ is that [the executives] don't understand the 
requirements for international students because they never taught really themselves.

Academic staff argued that the decreasing amount of support from nonacademic staff members meant it was falling back to the academic staff members to provide psychosocial and non-academic support for international students. One academic staff member was especially articulate about the process and generally claimed that having support staff members ensured that international students did not fall through the cracks and helped these students integrate better into the university system and feel part of the university culture.

We still have our student support officer at the moment but if we lose her and there isn't anyone down there [at student central] the students' first port of call will be us, which will mean that we will be inundated with students...centralisation of university services doesn't help to build a feeling of belonging to the university and each school tries very hard, I know ours does, to make a student feel part of the school, part of a student community and a student body so that they do have some sort of belonging which is really important for international students because they are out of their comfort zone and away from home. So we work really hard to do that but it's very difficult if you've lost your student support as well.

This view was supported by other academic staff members who suggested that the university executives did not have much contact with international students and so were out of touch with the challenges that front-line staff face when working with this cohort. The change in service provision, according to these staff, might only work for those high-level management staff that focus on the university's financial bottom line rather than the daily challenges that academic staff face providing support to international students.

\section{Miscommunication among Staff Members}

Staff members reported that they felt frustrated because the service provision changes were causing miscommunication among staff at faculty and school levels:

I think at the moment there's a lot of an inconsistency between different schools, different faculties, different advisers or whatever.

This led to misunderstandings between staff members and confusion over who was to handle specific issues or problems. From an International student support perspective, students were being sent to and from multiple interfaces with support services because staff were confused about which services were still being offered, which had in fact ceased, or where some services had moved.

The disconnect between centralised support and the "on-the-ground" knowledge of staff and needs of students was highlighted in one international student's narrative around having to return home at short notice. In her effort to learn her options regarding suspension/withdrawal of enrolment, university fees 
and student VISA implications, she was sent repeatedly between two different campuses of the university.

I was thinking about withdrawing from my course, and this was an option at this time. And [student central] said "are you an international student", "yes I am", so "no you have to talk to international student services information centre ${ }^{1}$." I called there and they said "no there's no one here that can answer your questions." We drove to [campus \#2 ${ }^{1}$ ], got there, a guy picked up the [internal] phone... and I said "I came here from [campus \#1] to see you," and explain[ed] all the things. On the phone he said "no, that's not me, you should go to international student services". I said "I just went there, they said that it's with you, can you see me?" "No, I can't see you. In 10 minutes I'm going home, and that's international services." So I went back. I got there, explained the whole situation again and they said "no there's another sector that's going to answer your questions." So I was feeling like ping-pong between all those people."

The international student re-telling this story then ended her account with a telling remark: "The service that they should provide that was international service, the guy was just rude and awful." Such an unconstructive staff response to deal with a student's issue is consistent with the staff views being expressed regarding their frustration at the loss of specialist knowledge (that comes with specialised services) in the new service provision model.

\section{Lack of Specialised Services}

The above views were echoed in multiple international students' stories regarding not knowing where to go to access services, and a lack of services meeting their needs at the university:

I am so busy with my research. It could have been better that I not have to worry about wasting time chasing people to extend my visa...they sent me everywhere. First I went to the faculty office and they told me...it's the responsibility of international office. I went there and they told me...to go to the student central. I was a bit annoyed because it was difficult to find someone specific to go to.

International students also indicated there was a lack of services that promoted cultural interaction or services that took into account the fact that some students may be dealing with isolation or loneliness, or pragmatic issues such as dietary restrictions:

No cultural events, no chances for people...I mean you have a lot of international students [here]; you can have some sort of maybe an international students day or something, where international students can come in their cultural costumes.

Some of the students, they're having a problem with food because they're Muslims. They're eating Hallal, especially when it's related with 
meat...when you're putting pork or ham in a sandwich, please make it very obvious because we don't eat pork and ham.

International students' comments regarding lack of specific services extended to perceptions of their academic and industry development. It was reported that they were not attaining study-related work experiences, and when they have tried to apply for jobs that were related to their studies, they had not been successful.

These students explained their feeling that it was the university's responsibility to line up possible work placements when such placements were required as part of their study, since the international students themselves would not be aware of how to go about seeking these types of jobs or employers might not be willing to use the service of international students without endorsement from institutions:

When I came here I found out that to graduate [with] my degree I have to do 12 weeks work experience. That's [an] issue because nobody's interested to hire international students....[my lecturers] said you can do this work experience in your own country as a solution, but I'm here in Australia to learn. I could do the whole degree in my country. Why am I here? There's no benefit. I'm here to learn.

\section{Conclusion and Implications}

One of the issues that began to emerge during the current study was associated with organization-wide changes in approaches to service provision. In the context of this change, staff and students alike expressed a growing dissatisfaction that not only was it already challenging to provide or utilize good support services, but that the loss of previous service pathways and, in particular, more specialised modes of interaction between staff and international students served to make the current situation even more frustrating. In the context of this growing disquiet, a theme that began to emerge from the staff was general dissatisfaction with a model that, in their opinion, did not benefit either staff or students.

Staff reported experiencing frustration with the mainstream model which was adding to their already heavy workload, characterised by lack of time and resources, and frequent miscommunication between staff members within and between faculties as well as between staff members and management (policy makers). If the aim of the move to the centralized model was towards efficiency, it would seem that from the accounts of some staff this aim had not been achieved as staff were confused as to which services were still in effect and where students in need should be sent. Further, the mainstream model of service provision was alienating some international students, who required more specific services to cater for their unique needs.

Two important implications arose from the above findings. Firstly, the accumulation of negative experiences reported by staff could lead to an 
increasing likelihood that these staff members will view international students in a negative manner or through a "deficit" lens, which then impacts on how they treat and work with these students.

Secondly, and related to the first implication, is that one outcome of not meeting the needs of international students and having some staff treat some international students using a deficit lens could be increased student attrition. Although the retention rate for $\mathrm{CU}$ in 2010 (the year prior to data collection) was $0.4 \%$ above their target and had increased slightly over the 2009 figure, it was below the national average of $84 \%$. This rate did not distinguish between international or domestic attrition; nevertheless, an attrition rate of more than $16 \%$ could have serious implications for CU, especially if it increases. There were, in fact, anecdotal reports from both interviewed staff and students of international students leaving $\mathrm{CU}$ and in some cases transferring to neighboring universities because of their negative experiences.

Ultimately, the positive benefits of intercultural interaction between staff and international students and between domestic and international students reported in literature will fail to occur if international student needs are not being met and these students opt to study elsewhere (Kell \& Vogl, 2008; Mahat \& Hourigan, 2007; Sam, 2001).

\section{Notes}

1. Both campuses form part of CU.

2. The "international student services information centre" is the only remaining remnant of the Case University International and is responsible (only) for enrolment of international students.

\section{References}

Arambewela, R., \& Hall, J. (2009). A comparative analysis of international education satisfaction using SERVQUAL. Journal of Services Research, 6, 141-163.

Australian Education International. (2010). International student barometer project: National project. Canberra, AU.

Baldwin, G. (1994). The Student as customer: The discourse of "Quality" in higher education. Journal of Tertiary Education Administration, 16(1), 125133. doi: $10.1080 / 1036970940160110$

Bean, J. P., \& Metzner, B. S. (1985). A conceptual model of non-traditional undergraduate student attrition. Review of Educational Research, 55(4), 485540 . 
Beaton-Wells, M., \& Thompson, E. (2011). The economic role of international students' fees in Australian universities. Melbourne, Australia: University of Melbourne.

Bochner, S. (1986). Coping with unfamiliar cultures: Adjustment or culture learning? Australian Journal of Psychology, 38(3), 347-358. doi: 10.1080/00049538608259021

Calder, A. (2004). Peer interaction in the transition process. Journal of the Australia and New Zealand Student Services Association, 23, 4-16.

Carroll, J., \& Ryan, J. (2005). Teaching international students: Improving learning for all. London; New York Routledge.

Charmaz, K. (2000). Grounded theory: Objectivist and constructivist methods. In N. K. Denzin \& Y. S. Lincoln (Eds.), Handbook of qualitative research (pp. 509-535). Thousand Oaks, CA: Sage.

Charmaz, K. (2006). Constructing grounded theory: A practical guide through qualitative analysis. London, UK: Sage.

Conway, T., Mackay, S., \& Yorke, D. (1994). Strategic planning in higher education: Who are the customers? International Journal of Education Management, 8(6), 29-36. doi: 10.1108/09513549410069202

David, S., \& Renea, F. (2008). Predictors of first-year student retention in the community college. Community College Review, 36(2), 68-88.

Department of Education Employment and Workplace Relations (DEEWR). (2008). Administrative information for providers: Student support. Canberra $\mathrm{AU}$.

de Wit, H. (Ed.). (1995). Strategies for internationalisation of higher education: A comparative study of Australia, Canada, Europe and the United States of America. Amsterdam: EAIE.

Dhillon, J., McGowan, M., \& Wang, H. (2008). How effective are institutional and departmental systems of student support? Insights from an investigation into the support available to students at one English university. Research in PostCompulsory Education, 13(3), 281-293. doi: 10.1080/13596740802346472

Forbes- Mewett, H. (2008). Mainstreaming international student support services: Where's the 'McValue'? School of Social Sciences, La Trobe University. Melbourne. Retrieved from http://www.tasa.org.au/uploads/2011/01/ForbesMewett-Helen.pdf

Fossey, E., Harvey, C., McDermott, F., \& Davidson, L. (2002). Understanding and evaluating qualitative research. Australian and New Zealand Journal of Psychiatry, 36, 717-732. doi: 10.1046/j.1440-1614.2002.01100.x

Franke, A., \& Arvidsson, B. (2010). Research supervisors' different ways of experiencing supervision of doctoral students. Studies in Higher Education, 36(1), 7-19. doi: 10.1080/03075070903402151 
Glesne, C. (1999). Becoming qualitative researchers: An introduction. Sydney, Australia: Addison Wesley Longman.

Gudykunst, W. B. (1998). Bridging Differences: Effective Intergroup Communication. Thousand Oaks: Sage Publications.

Hill, F. M. (1995). Managing service quality in higher education: The role of the student as primary consumer. Quality Assurance in Education, 3(3), 10-21. doi: 10.1108/09684889510093497

Kell, P., \& Vogl, G. (2008). Perspectives on mobility, migration, and well-being of international students in the Asia- Pacific. International Journal of Asia-Pacific Studies, 4(1), v-xviii.

Lynch, K. (2006). Neo-Liberalism and marketisation: The implications for higher education. European Educational Research Journal, 5(1), 1-17. doi: 10. 2304/eerj.2006.5.1.1

Mahat, M., \& Hourigan, C. (2007). International student experience: What it is, what it means and why it matters? Paper presented at the Australasian Association for Institutional Research Conference, Sydney, NSW. Retrieved from http://www.aair.org.au/2006Papers/Mahat.pdf

Manis, J., \& Meltzer, J.G. (1972). Symbolic interaction: A reader in social psychology (2nd ed.). Boston, MA: Allyn and Bacon.

Marginson, S. (2007). University mission and identity for a post post-public era. Higher Education Research \& Development, 26(1), 117-131. doi: 10.1080/ 07294360601166851

McKenzie, P. (2008). Key international developments affecting Australian education and training. Clayton Vic: Monash University - ACER Centre for the Economics of Education and Training (CEET).

McKinlay, N. J., Pattison, H. M., \& Gross, H. (1996). An exploratory investigation of the effects of a cultural orientation programme on the psychological wellbeing of international university students. Higher Education, 31(3), 379-395.

Meek, L. (2000). Diversity and marketisation of higher education: Incompatible concepts? Higher Education Policy, 13, 23-39. doi: 0952-8733/00

Mehdizadeh, M., \& Scott, G. (2005). Adjustment problems of Iranian international students in Scotland. International Education Journal, 6, 484-493.

Moghaddam, A. (2006). Coding issues in grounded theory. Issues in Educational Research, 16(1), 52-66.

Moodie, G. (2010). The developing student market in Australian higher education. In R. Brown (Ed.), Higher education and the market. Hoboken, NJ: Routledge.

Morse, J. (1995). The significance of saturation. Qualitative Health Research, 5 147-149. doi: 10.1177/104973239500500201 
Oldfield, B., \& Baron, S. (2000). Student perceptions of service quality in a UK university business and management faculty. Quality Assurance in Education, 8(2), 85-95. doi: 10.1108/09684880010325600

O'Neill, M. A., \& Palmer, A. (2004). Importance-performance analysis: A useful tool for directing continuous quality improvement in higher education. Quality Assurance in Education, 12(1), 39-52. doi: 10.1108/09684880410517423

Paige, R. M. (1990). International students: cross-cultural psychological perspectives. In R. W. Brislin (Ed.), Applied cross-cultural psychology (pp. 161-185). Newbury Park, CA: Sage.

Pelletier, C. (2004). The experiences of international students in UK higher education: A review of unpublished research. London, UK: UKCOSA.

Phillimore, J., \& Koshy, P. (2010). The economic implications of fewer international higher education students in Australia. Perth, Australia: John Curtin Institute of Public Policy.

Pimpa, N. (2003). Development of an instrument for measuring familial influence on Thai students' choices of international education. International Education Journal, 4(1), 178-192.

Pitman, T. (2000). Perceptions of academics and students as customers: A survey of administrative staff in higher education. Journal of Higher Education Policy and Management, 22(2), 165-195.

Rahman, O., \& Rollock, D. (2004). Acculturation, competence, and mental health among South Asian students in the United States. Journal of Multicultural Counseling and Development, 32(3), 130-142. doi: 10.1002/j2161-1912. 2004.tb00366

Ramachandran, N. T. (2010). Marketing framework in higher education: Addressing aspirations of students beyond conventional tenets of selling products. International Journal of Educational Management, 24(6), 544-556. doi: 10.1108/09513541011067700

Ramsey, S., Jones, E., \& Barker, M. (2007). Relationship between adjustment and support types: Young and mature-aged local and international first year university students. Higher Education, 54, 247-265. doi: 10.1007/s10734-0069001-0

Sam, D. L. (2001). Satisfaction with life among international students: An exploratory study. Social Indicators Research, 53(3), 315-337. doi 10.1023/ A:1007108614571

Schulz, L., \& Szekeres, J. (2008). Service provision to students: Where the gown best fits. Journal of Higher Education Policy and Management, 30(3), 261271. doi: $10.1080 / 13600800802155150$

Scott, S. V. (1999). The academic as service provider: Is the customer "always right"? Journal of Higher Education Policy and Management, 21(2), 193-202. doi: $10.1080 / 1360080990210206$ 
Searle, W., \& Ward, C. (1990). The prediction of psychological and sociocultural adjustment during cross-cultural transitions. International Journal of Intercultural Relations, 14(4), 449-464.

Seow, M. A. (2006). The role of the international student advisor-- how we have changed. Proceedings of the 17th ISANA International Education Conference, Sydney. Retrieved from http://www.proceedings.com.au/isana/docs/2006/ Paper_seow.pdf

Sines, R. G. J., \& Duckworth, E. A. (1994). Customer service in higher education. Journal of Marketing for Higher Education, 5(2), 1-15. doi: 10.1300/J050 v05n02_01

Small, K. (2008). Relationships and reciprocality in student and academic services. Journal of Higher Education Policy and Management, 30(2), 175185. doi: $10.1080 / 13600800801938770$

Strauss, A., \& Corbin, J. (1990). Basics of qualitative research: Grounded Theory procedures and techniques. Thousand Oaks, CA: Sage.

Tan, K. C., \& Kek, S. W. (2004). Service quality in higher education using an enhanced SERVQUAL approach. Quality in Higher Education, 10(1), 17-24. doi: 10.1080/1353832242000195032

Tinto, V. (1975). Dropout from higher education: A theoretical synthesis of recent research. Review of Educational Research, 45(1), 89-125.

Trice, A. (2003). Faculty perceptions of graduate international students: The benefits and challenges. Journal of Studies in International Education, 7(4), 379-403. doi: $10.1177 / 1028315303257120$ 